
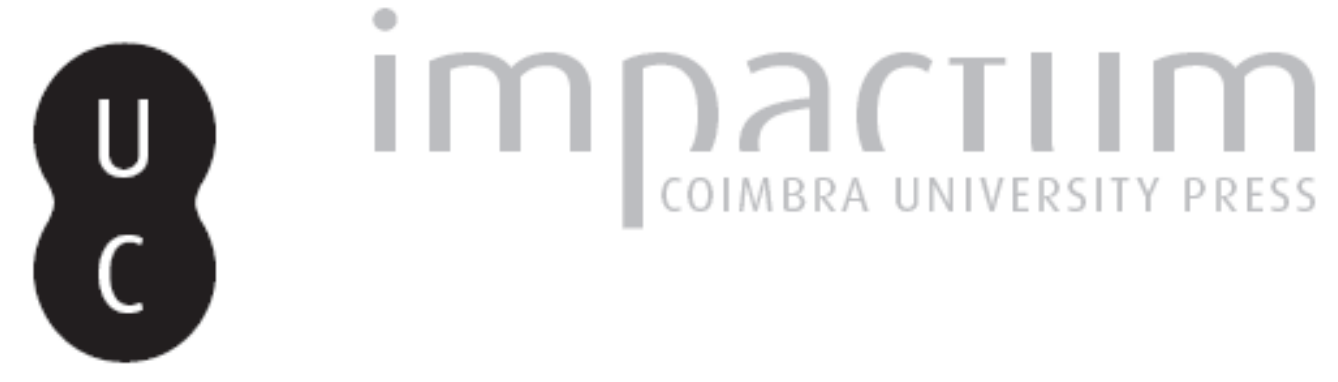

\title{
Um elogio da cidade de Coimbra e dos Colégios de Jesus e das Artes
}
Autor(es): $\quad$ Urbano, Carlota Miranda
Publicado por: Associação Portuguesa de Estudos Clássicos; Instituto de Estudos Clássicos
URL persistente:
URI:http://hdl.handle.net/10316.2/30447
DOI:
DOI:http://dx.doi.org/10.14195/0872-2110_51_12
Accessed : $\quad$ 26-Apr-2023 16:18:43

A navegação consulta e descarregamento dos títulos inseridos nas Bibliotecas Digitais UC Digitalis, UC Pombalina e UC Impactum, pressupõem a aceitação plena e sem reservas dos Termos e Condições de Uso destas Bibliotecas Digitais, disponíveis em https://digitalis.uc.pt/pt-pt/termos.

Conforme exposto nos referidos Termos e Condições de Uso, o descarregamento de títulos de acesso restrito requer uma licença válida de autorização devendo o utilizador aceder ao(s) documento(s) a partir de um endereço de IP da instituição detentora da supramencionada licença.

Ao utilizador é apenas permitido o descarregamento para uso pessoal, pelo que o emprego do(s) título(s) descarregado(s) para outro fim, designadamente comercial, carece de autorização do respetivo autor ou editor da obra.

Na medida em que todas as obras da UC Digitalis se encontram protegidas pelo Código do Direito de Autor e Direitos Conexos e demais legislação aplicável, toda a cópia, parcial ou total, deste documento, nos casos em que é legalmente admitida, deverá conter ou fazer-se acompanhar por este aviso.

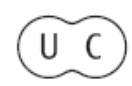




\section{Boletim de}

\section{Estudos Clássicos}

Associação Portuguesa de Estudos Clássicos Instituto de Estudos Clássicos

Coimbra

Junho de 2009 


\section{UM Elogio da Cidade de COIMBRA E dOS COLÉGIOS DE JESUS E DAS ARTES}

Nos últimos dois números do Boletim de Estudos Clássicos apresentámos excertos de uma epopeia neolatina do séc. XVII, a Paciecidos ${ }^{1}$ do P.e Bartolomeu Pereira S.J., excertos dedicados respectivamente ao elogio da cidade de Goa e da cidade de Macau. Tratando-se de uma epopeia que pretende celebrar a acção missionária da Companhia de Jesus, num caso, como no outro, observámos que o motivo literário do elogio da cidade, tema recorrente na Literatura neolatina, serve de pretexto para o louvor de casas ou colégios da Companhia naquelas cidades.

O excerto que trazemos a este número do Boletim de Estudos Clássicos é relativo à cidade de Coimbra e ao Colégio de Jesus, a casa da Companhia onde o herói da epopeia fez o seu noviciado, de onde partiu para a missão no Oriente (como muitos outros) e onde o autor do poema, o padre Bartolomeu Pereira, exerceu o seu ministério durante vários anos, inclusive no ano em que o seu poema foi publicado.

O elogio da cidade e do Colégio da Companhia tem lugar durante a longa narrativa analéptica em que o herói do poema relata aos companheiros, entre outras coisas, a sua chegada a Coimbra, para aí fazer o noviciado na Companhia de Jesus, depois de ter estudado alguns anos no Colégio de $\mathrm{St}^{\circ}$ Antão em Lisboa, onde o exemplo dos mestres o moveu a dar esse passo.

Recorrendo à antiga e tradicional imagem cristã da militia Christi que a literatura jesuítica assumiu plenamente como traço identitário, o poeta coloca na boca do herói estas palavras que explicam a sua chegada a Coimbra e ao Colégio de Jesus:

"Então, alisto o meu nome na milícia sagrada, que tem por general no governo das armas Jesus Cristo, e que as puras e níveas bandeiras adornam.

1 Pereira, Bartolomeu, Paciecidos: libri duodecim: decantatur clarissimus P. Franciscus Paciecus Lusitanus, Pontlimiensis, è Societate Iesu, Japponiae Provincialis eiusdem Ecclesiae Gubernator, ibique uiuus pro Christi fide lento concrematus anno 1626. Conimbricae, Expensis Emmanuelis de Carvalho 1640. 
Feliz, recebo ordens para me mudar daquela cidade para os lugares de Hércules, onde o Mondego entra pelos campos adentro, derramando-se em prata; onde, cingida na cabeça com o fértil ramo de oliveira, se ergue ao céu a douta Coimbra."2

O elogio da cidade concentra-se em breves versos que, a despeito de breves, evocam a sua origem miticamente associada a Hércules e assinalam a tradicional imagem renascentista de Coimbra como cidade do saber. O ramo de oliveira que lhe orna a fronte identifica-a com Minerva, a deusa da Sabedoria, que é frequentemente nos textos desta época metonímia da Universidade. A 'douta Coimbra' que se ergue ao céu ostenta numa das suas colinas a Casa do Colégio de Jesus. Em certa medida, o elogio do colégio reverte-se no louvor da cidade. Com base no locus a minore ad maius, louvando-se a parte, louva-se o todo.

“Aí, numa esplêndida colina, ergue-se a elevada mansão [do Colégio] de Jesus que, sobranceira à cidade, contempla os campos. Dotou-a o nosso fundador Loiola, para que fosse entre todas as casas a única, a mais antiga no nascimento, a primeira em idade e em honra, e continuamente a foi cumulando de novos aumentos.

Assim que dentro das muralhas de Roma nasceu a nossa Companhia, $\log$ o el'Rei D. João, o Terceiro de seu nome, não o segundo em piedade, e o primeiro na glória e na honra, fundou para nós esta casa. Das suas fundações saiu de repente um enxame de abelhas que, em alegre zumbido, voando, atravessou os ares cristalinos, augúrio e presságio de bons começos: os enxames de companheiros que por terra e por mar em alegre alvoroço haviam de espalhar pelo mundo a lei dos Céus.

Longe o cavalo de que se orgulham os muros beligerantes da guerreira Cartago e os Capitólios ${ }^{3}$ que se louvam de ser o governo da

2 "Ergo militiae huic sacrae, cui ductor Iesus/ Arma regit, castaeque niues uexilla decorant/ Do nomen, laetusque illa digressus ab urbe/ Mittor in Herculeos tractus, qua Monda per agros/ Influit argento fugitiuo, oleaque feraci/ Cincta caput, caelo doctrix Collimbria surgit" (VII, 73-78).

3 'capitolia', no plural. O poeta quer com os 'capitólios' significar todos aqueles que, à imagem do Capitólio de Roma, pensam governar o mundo. Por 
raça humana. Estes prodígios não podem erguer-se da terra, mas [aquele] enxame sobe em direcção aos altos céus.

Graças aos bens e ao alento dos nossos reis, surgem estes elevados palácios, que se erguem como se fossem os edifícios de uma grande cidade. De um lugar elevado resplandece o Liceu, consagrado aos filhos de Minerva, ao longe desvendam-se os átrios, apoiados em trezentas colunas de mármore, para onde dizem que as Musas se mudaram deixando o monte de Pindo, para onde Mercúrio levou os seus lares e Palas mudou Atenas e a instalou amplamente num monte de oliveiras. Que Virgílios aqui [se encontram] com eloquente Cícero, quantos notáveis pela pena de Tácito! Como floresce a sabedoria de Aristóteles! Recordo os eloquentes Ambrósios em matéria sagrada, e quantos Agostinhos tem esta casa. E certamente ainda é pouco, se eu quiser contar estes espíritos brilhantes, eles ultrapassam em valor as areias da praia e as estrelas do céu. Daqui um exército dominará o mundo contra o Báratro. Oh, que grandes generais e poderosas falanges esta casa (cavalo de Tróia vitorioso que se abre) envia para a vida! Brilha cada vez mais o [seu] fogo no mundo já em chamas e surge uma imagem maior que a dessa Tróia. Enumerá-los a todos seria muito demorado..."4

oposição a estas edificações 'mudanas', exalta-se a edificação da casa da Companhia que nasce para fins 'espirituais'.

4 "Vix nostra est magnis Romae sub moenibus orta/ Relligio, nobis cum Rex haec tecta Ioannes,/ Tertius ille annis, nulli pietate secundus,/ Et fama et titulis primus, fundauit; ab ipsis/ Caementis examen apum cum murmure laeto/ Erupit, liquidasque uolans euasit in auras;/ Augurium, auspiciisque omen felicibus, illinc/ Per mare, per terras sociorum examina laeto/ Applausu legem aetheream allatura per orbem./ I procul, armisonae si quod Carthaginis arces/ Bellatoris equi, si quod Capitolia iactant/ Humanae gentis caput; haec non se omina possunt/ Tollere humo; it caeli superas examen ad auras./ Diuitiis animisque altae regalibus aedes/ Consurgunt, magnaeque urbis se molibus instar/ Attollunt; radiat celsa de parte Lycaeum/ Palladiae genti sacrum, longeque patescunt/ Atria, marmoreis ter centum effulta columnis,/Quo migrasse ferunt Pindi de uertice Musas/ Mercuriusque lares, et late Pallas Athenas/ Transtulit, et sedes olearum in monte locauit./ Fecundo quales hic cum Cicerone Marones!/ Quot Taciti calamo insignes! Quantusque sophia/ Floret Aristoteles! memorem quid sacra loquentes/ Ambrosios? Quantosque ferat domus Augustinos?/ Parua quidem haec; animi referam si lumina, arenas/ Litoris, et coeli superant uirtutibus astra./ Hinc orbem domiturae acies, contraque Barathrum/ Proh 


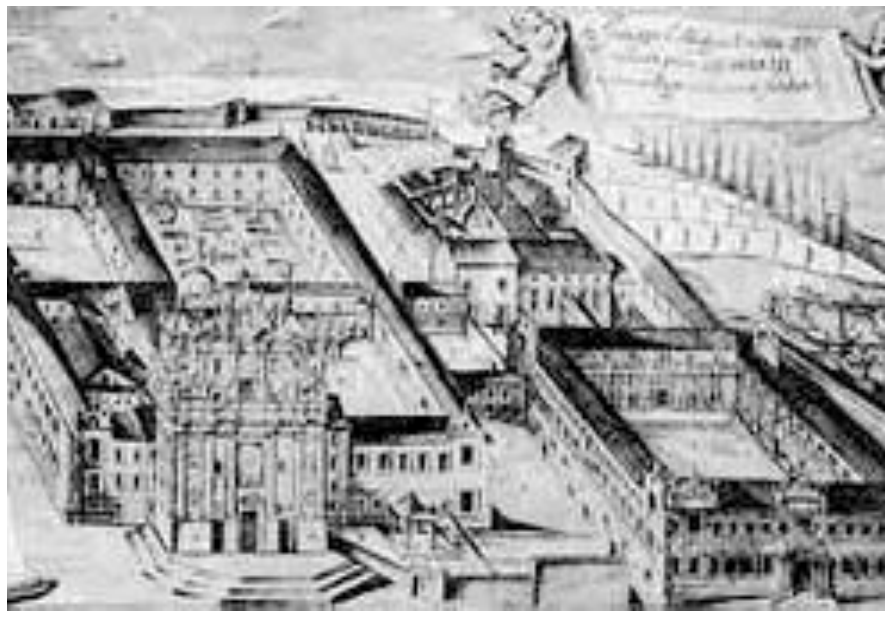

O Colégio de Jesus, fundado em 1542, foi, na verdade, o primeiro Colégio da Companhia em todo o mundo. Desde 1544, por concessão de D. João III, os seus colegiais beneficiavam dos mesmos 'privilégios, liberdades, graças e franquezas' que os 'lentes, deputados e conselheiros da Universidade da cidade de Coimbra' 5 recebiam do Rei. Instalado provisoriamente na rua que lhe herdou o nome de 'Couraça dos Apóstolos' assim eram conhecidos os sacerdotes da Companhia de Jesus -, o Colégio que desempenharia um papel de relevo na formação de várias gerações de jesuítas, portugueses e não só, mereceria da munificência de D. João III a construção de um grande e complexo edifício que bastasse à instalação condigna de duas centenas de colegiais e respectivo pessoal auxiliar, como

quantos domus ista duces, fortesque phalanges/ Troianus seu uictor equus patefactus ad auras/ Emittit! Late splendent incendiai n orbe/ Fumanti, apparet Troiae iam maior imago./ Longum cuncta sequi...". VII, 84-116.

5 Conforme citação de Vasconcelos, António de, "Os Colégios Universitários", Secç.II-B), III, Colégio de Jesus, in Escritos Vários, 2 vol, Arquivo da Universidade de Coimbra, reedição de M. A. Rodrigues, Coimbra, 1987. Cfr. I, 190. Sobre este Colégio, encontra-se informação mais detalhada na obra de Francisco Rodrigues S.J., História da Companhia de Jesus na Assistência de Portugal, 4 tomos, Porto, 19381950. 
pretendiam os planos joaninos de propagar e consolidar o cristianismo no cada vez mais vasto território onde se jogava o domínio português.

Deste Colégio sairiam gerações e gerações de missionários, que, seguindo a exploração do imaginário da militia Christi, o poeta designa como um verdadeiro exército contra os poderes do Báratro: a heterodoxia que grassava na Europa e a idolatria nos novos mundos de missão. O Colégio e a missão educativa da Companhia de Jesus é, assim, um novo 'cavalo de Tróia' que lança no mundo um exército de soldados contra os poderes infernais; soldados que incendeiam o mundo, aqui comparado a Tróia em chamas, com o lume da palavra de Deus. A imagem bíblica do fogo pode ter aqui uma dupla leitura, a de fogo devorador e purificador das impurezas e a do fogo do Espírito, o próprio Deus, que vivifica e incendeia o mundo. À imagem da narrativa do Pentecostes, estes apóstolos também incendeiam estoutra Tróia. ${ }^{6}$

Foi augúrio daquele exército o enxame de abelhas que se ergueu nos ares aquando do lançamento das suas fundações. Augúrio superior à cabeça de cavalo que Dido encontra na fundação de Cartago e que prenuncia as qualidades guerreiras da futura cidade.

Depois de descrever a monumentalidade do edifício, o poeta evoca a grandeza intelectual do Colégio. Enumera então os seus 'Virgílios, Cíceros, Aristóteles, Ambrósios, Agostinhos,' metonímia dos mestres que nele ensinam e se formam.

Julgamos que Bartolomeu Pereira se refere não só ao Colégio de Jesus mas também ao Colégio das Artes que D. João III confiara ao governo e magistério da Companhia desde 1555. Com efeito, embora os dois colégios tivessem fins distintos - o Colégio de Jesus, a formação dos membros da Companhia e o das Artes a formação em Artes e Humanidades aberto ao público da Universidade - a Companhia acabava por designar a ambos como 'Colégio de Coimbra', como o documenta a legenda da gravura que acima reproduzimos: Imago collegii in Societate IESU omnium primi a IOANNE III Lusitaniae rege Conimbriae fundati.

${ }^{6}$ A narrativa do Pentecostes (Act. 2, 1-4) identifica o Espírito com as 'línguas de fogo'. Para outras imagens de Deus como fogo veja-se por exemplo: Dt 4, 24 "Porque o Senhor, vosso Deus, é um fogo devorador, um Deus zeloso"; Jer. 23, 29: "Não se assemelham ao fogo as Minhas palavras - oráculo do Senhor - como um martelo que tritura a rocha?"; Lc, 12, 49: Vim lançar fogo sobre a terra; e que quero eu senão que ele já se tenha ateado?". 
O Colégio das Artes teve desde a fundação as suas primeiras instalações, de carácter provisório, nas imediações do Mosteiro de $\mathrm{St}^{\mathrm{a}} \mathrm{Cruz}$, nos colégio de S. Miguel e de Todos os Santos, ${ }^{7}$ emprestados para o efeito pelo dito Mosteiro, enquanto se construía um edifício de raiz também na zona baixa da cidade - onde por sua vez se viria a instalar o tribunal do Santo Ofício em Coimbra. Mas o Real Colégio das Artes acabou por merecer um novo edifício na zona alta da cidade. Por essa instalação lutaram os padres da Companhia que, divididos entre o Colégio de Jesus na alta - onde residiam mestres e alunos da Companhia - e o Colégio das Artes na baixa frequentado por grande número de alunos - em 1566 conseguiram transferir este último para a alta, instalando-o provisoriamente na vizinhança do Colégio de Jesus. Projectou-se depois a construção de um edifício novo cuja primeira pedra foi lançada em 1568, e a que se refere Bartolomeu Pereira ao louvar os átrios apoiados nas 'trezentas colunas de mámore', para onde se mudaram as Musas. A construção deste edifício grandioso tardou largos anos, porque interrompida por falta de recursos, como descreve Francisco Rodrigues na sua História da Companhia de Jesus na Assistência de Portugal. ${ }^{8}$ Só no séc. XVII seriam retomados e concluídos os trabalhos, e inaugurado o edifício no ano de $1616 .{ }^{9}$

Do Real Colégio das Artes, ainda hoje se pode admirar o pátio de planta quadrangular, rodeado de um quadri-pórtico, cujas colunas são visíveis também na gravura do séc. XVIII que aqui reproduzimos. Esta gravura mostra ainda dois 'passadiços' que foram depois construídos, um dos quais para fazer a ligação entre os dois edifícios: do Colégio de Jesus ao Colégio das Artes. No edifício deste último funcionariam, de meados do séc. XIX em diante, os Hospitais da Universidade (até aos anos 80 do séc. XX).

Em outros textos do séc. XVII os padres da Companhia referem-se, pois, ao 'Colégio da Companhia' incluindo nessa referência o Colégio das Artes e o de Jesus que se destinava especificamente à formação dos seus membros.

Nos próprios catálogos trienais da província portuguesa enviados para Roma com o elenco dos membros de cada casa da província, pelo menos nos que consultámos para perseguir o rasto do Padre Bartolomeu Pereira, o

${ }^{7}$ Onde hoje se encontra o edifício da Caixa Geral de Depósitos.

8 Rodrigues S.J., Francisco, História da Companhia de Jesus na Assistência de Portugal, Porto, 1938, t. II, vol. 1, p. 139-164.

${ }^{9}$ Cfr. ibidem t. II, vol. 2, p. 249. 
Colégio de Jesus é geralmente designado como Collegium conimbricense, ou em português, como 'Collegio de Coimbra'. Já o Colégio de St. Antão, em Lisboa, é designado precisamente como 'Collegio de St. ${ }^{\circ}$ Antão'. ${ }^{10}$

Quando Bartolomeu Pereira compôs o Paciecidos, na parte final da primeira metade do séc. XVII, já os dois colégios funcionavam lado a lado nos edifícios a que nos referimos. Os últimos versos do seu elogio são dedicados à capela do Colégio de Jesus, a última parte do edifício a ser construída, igreja cujo orago são as onze mil virgens e que hoje é a 'Sé Nova' de Coimbra.

Colocada na narrativa analéptica do herói e, portanto, reportando-se aos anos do noviciado e restante formação de Francisco Pacheco, de 1585 a 1592, ano em que partiu para a Índia, a descrição da igreja recorre ao artifício da visão onírica e futura para evitar anacronismos. Com efeito, a primeira pedra deste templo foi solenemente benzida em 1598, quando o herói da epopeia já tinha partido para o Oriente, de onde não voltaria. Ao longo de meio século foi sendo construída a nave central que foi benzida solenemente no dia 31 de Dezembro de 1639 e inaugurada no dia 1 de Janeiro de 1640, o dia do Santíssimo Nome de Jesus, orago do Noviciado da Companhia de Jesus em Coimbra. Completam-se em breve 370 anos sobre este acontecimento e, curiosamente, sobre a própria publicação do Paciecidos que por sua vez assinalava então um século de vida sobre a aprovação formal da Companhia de Jesus.

Bartolomeu Pereira conhecia, então, a construção que naquela data se inaugurava e que ainda ficaria incompleta (faltava a longa construção do transepto com o moroso zimbório e a construção do altar-mor) até à conclusão do edifício, inaugurado em 31 de Julho de 1598. Segundo informa A. Vasconcelos no estudo a que já fizemos referência, ${ }^{11}$ as obras ainda continuariam, quer na execução da parte superior da fachada quer no douramento das talhas de vários altares.

10 Arsi (Archiuum romanum Societatis Iesu) Lus. 44 I-II: Catálogos trienais da província portuguesa (1587-1645).

${ }^{11}$ Cfr. op. cit. p. 193-194. Veja-se também a monografia sobre esta igreja que, numa perspectiva histórica e artística, vem dar-lhe justa atenção: Coutinho, José Eduardo Reis, Sé Nova de Coimbra Colégio das Onze mil Virgens-Igreja dos Jesuítas, ed. Paróquia da Sé Nova, Coimbra, 2003. 
Assim, e como acima ficou dito, para poder fazer o elogio da igreja do colégio, o herói, que recorda a casa onde fez o noviciado, contempla uma visão do futuro e descreve a grandiosidade quer do que já, na realidade, existia, quer do que se adivinhava no projecto.

“(...)mas que chama, que ardor me anima? Quem me arrebata? Sou arrastado para as nuvens e a minha alma bebe das fontes celestiais os presságios do futuro; experimento o furor dos astros, e já me parece que vou para além das leis do tempo e que adivinho os próximos incrementos do santuário. A elevada igreja, mansão dos santos, ergue-se em mole soberba sob magnífica abóbada; Aqui as mãos da arte nos impediram de celebrar a antiga Corinto. Oh! Erguem-se os mármores artisticamente trabalhados, a pintura supera a obra de Apeles. Templo algum tem uma fachada tão trabalhada; três portas resplandecem à entrada, e a maior sustenta, no mármore brilhante, o nome de Jesus gravado a ouro. Vêem-se conchas sublimes, e sob um vitral da Bretanha, refulge uma larga janela, para que não falte à igreja o espelho da beleza; à volta, e por cima, florescem na pedra ramagens e flores bem torneadas. Os famosos retratos dos nossos: em cima resplandece o Cantábrio, o nosso fundador, de um lado brilha Xavier, do outro, mostrando a morte da rainha, está o nobre duque de Gandia, e a seus pés Gonzaga tece uma coroa. As suas paredes elevam-se atravessando os ares, e de um lado e de outro erguem-se ao céu duas torres, e nestas torres, estão em simetria S. Pedro com as chaves, e S. Paulo resplandecendo com a espada cintilante. Louco o trabalho das pirâmides, e os monstros biformes! Coroam todo o edifício as armas dos Reis de Portugal, sobre o colo soberbo e as penas de um magnífico Serafim. E uma grande cruz, enfim, a meta última, abençoa os últimos trabalhos. Ocultando sobre os astros dos céus a sua cabeça, fala com todo o Olimpo e com os santos seus vizinhos."12

12 “(...) sed quae flamma excitat ardor?/ Quis rapit? In nubes feror, et praesaga futuri/ Mens bibit aethereos haustus, patiorque furores/ Sidereos; leges supra mihi temporis ire/ Iam uideor, templique auctus prescire futuros./ Molibus erigitur Superum domus alta superbis/ Fornice sub magno; ueterem celebrare Corinthum/ Hic artis uetuere manus, proh! Daedala surgunt/ Marmora; Apelleos uincit pictura labores./ Non usquam templi facies operiosior; ardent/ Tergemini portarum aditus, maiorque nitenti/ Marmore inauratum sustentat nomen Iesus./ Elatae apparent 
Embora reconheçamos nesta descrição os traços fundamentais da fachada da Igreja do Colégio de Jesus, hoje Sé Nova de Coimbra, alguns pormenores não coincidem com o que ela veio a ser. Traçada segundo o protótipo da Igreja de Jesus em Roma, modelo inspirador de muitas outras da Companhia, a sua fachada monumental e austera ostenta realmente em quatro nichos as estátuas de $\mathrm{St}^{\circ}$ Inácio (o Cantábrico), de S. Francisco Xavier, S. Luís de Gonzaga, (cuja coroa simboliza o seu voto de virgindade feito ainda na infância) e São Francisco de Borja (o 'nobre duque de Gandia') que mostra a morte da rainha, aludindo ao célebre episódio em que, ao ver o cadáver da imperatriz, decide 'não mais servir senhor que morra'. Numa terceira ordem da fachada, lá estão, realmente, as estátuas monumentais de S. Pedro e S. Paulo e as armas dos reis de Portugal sobre as asas e o rosto de um anjo. Encima a fachada uma cruz, mas as iniciais IHS, gravadas a ouro sobre a porta principal e o vitral da Bretanha, são pormenores que não identificamos hoje naquele edifício. A Carta Ânua de $1639-1640^{13}$ faz referência a um incêndio em que um jovem estudante salvou as imagens de Nossa Senhora e de S. Miguel. A mesma carta refere-se, a propósito de umas celebrações no dia de S. Francisco de Xavier, aos vitrais e relíquias da igreja (fol. 226 v). Teriam existido realmente tais vitrais? As referências aos 'mármores' devemos entendê-las como recurso expressivo. Bartolomeu Pereira quer referir-se, naturalmente, à pedra em que o templo está construído.

Com o destaque que na epopeia se concede ao elogio de Coimbra e do 'Colégio da Companhia' (vv. 73-144), Bartolomeu Pereira oferece-nos uma imagem da importância desta casa da Companhia de Jesus na Província

conchae, subterque Britanno/ Plurima sub uitro pellucet ianua, pulchrae/ $\mathrm{Ne}$ desit speculum domui; circumque supraque/ Et rami et teretes uiuunt in marmore flores./ Nostrorum clarae effigies, Cantabrius alte/ Elucet genitor, nitet hinc Xauerius, illinc/ Reginae letum ostentans, dux inclytus adstat/ Gandiae, pedibusque terit Gonsaga coronam./ Aera per uacuum paries consurgit; utrinque/ Stant arces caelo elatae; stant arcibus aequi/ Claue Petrus, Paulusque ardens mucrone corusco./ Pyramidum labor insanus, laruaeque biformes./ Omne opus hoc regum lusorum stemmata, magni/ Colla super Seraphim plumasque elata, coronant./ Hic tandem extremos crux, ultima meta, labores/ Magna beat, caelique caput super astra recondens,/ Vicinos superos totumque effatur Olympum.” VII, 116-144.

13 ARSI, Lus. 53, Litt. Annuae, fol. 223-228. 
portuguesa. E essa importância vem-lhe não só do facto de o Colégio de Jesus ser o primeiro na história da Companhia, mas também do facto de nele, e no Colégio das Artes, se terem formado e ensinado nomes que se notabilizariam no campo científico e intelectual e figuras carismáticas do ponto de vista espiritual; pelo facto de nesta casa terem nascido escolas do saber que continuam a despertar o interesse de investigadores (como o curso filosófico dos Conimbricenses); de nele ter havido lugar a expressões e tradições artísticas (como o teatro) que se perpetuaram no tempo e estenderam, não só à Europa, mas ao mundo herdeiro da cultura ocidental.

CARLOTA MIRANDA URBANO 